Renato V. Samala, MD, MHPE,

FACP, FAAHPM

Department of Palliative and Supportive Care

Taussig Cancer Institute, Cleveland Clinic,

Cleveland, $\mathrm{OH}$; Assistant Professor, Cleveland

Clinic Lerner College of Medicine of Case Western

Reserve University, Cleveland, $\mathrm{OH}$
Ruth L. Lagman, MD, MPH, MBA,

FACP, FAAHPM

Department of Palliative and Supportive Care,

Taussig Cancer Institute, Cleveland Clinic, Cleve-

land, OH; Clinical Assistant Professor, Cleveland

Clinic Lerner College of Medicine of Case

Western Reserve University, Cleveland, $\mathrm{OH}$
Sina Najafi, DO

Staff Physician, Supportive and Palliative

Care, Baylor Scott \& White Health,

Dallas, TX
Flannery Fielding, CNP, MSN

Department of Palliative and Supportive

Care, Taussig Cancer Institute,

Cleveland Clinic, Cleveland, OH

\title{
Frequently asked questions about managing cancer pain: An update
}

\section{ABSTRACT}

Most patients with cancer experience pain at some point in the disease course due to the disease itself or its treatment, or both. Pain management can involve pharmacologic (nonopioid medications, adjuvants, and opioids) and nonpharmacologic (radiation therapy, interventional procedures) therapies. This article provides a treatment approach to reduce pain for patients with cancer and improve their quality of life.

\section{KEY POINTS}

Cancer pain affects patients throughout the disease trajectory.

The typical pharmacologic regimen for treating patients with cancer pain consists of an assortment of nonopioid analgesics, adjuvant pain medications, and opioids.

Early consideration of radiation therapy and various interventional pain management procedures can optimize pain control and preclude escalation of opioids.

New or worsening pain in patients with a history of cancer requires thorough assessment for cancer recurrence or progression.
Cancer-Related pain, resulting from the disease itself, its treatment, or both, is one of the disease's most agonizing symptoms, severely diminishing quality of life. A review of 52 studies published from 2005 to 2014, with 32,261 patients, concluded that $50.7 \%$ of patients with cancer experienced pain. ${ }^{1}$ In those who completed curative treatment, the prevalence of pain was $39.3 \%$, in those receiving anticancer therapy it was $55 \%$, and in those with advanced, metastatic or terminal disease it was $66.4 \%$.

Because cancer-related pain occurs throughout the course of the disease, primary care providers are likely to be called on to manage cancer pain, either in the outpatient or inpatient setting. Whether the provider is caring for a patient around the time of diagnosis, during treatment, at the terminal phase, or in survivorship, effective treatment of cancer pain helps patients achieve optimal quality of life. Knowledge of therapeutic approaches and both pharmacologic and nonpharmacologic alternatives may also assist clinicians in treating patients before partnering with specialists, such as those in oncology, palliative medicine, and pain management.

In an earlier article in this journal, Induru and Lagman ${ }^{2}$ stressed that effectively managing cancer pain can lead to overall improvement in patient satisfaction and quality of life. They explored the use of drugs such as opioids and adjuvant pain medications and nonpharmacologic measures such as acupuncture, massage therapy, and music therapy. This article builds on the previous review and features novel drugs and 


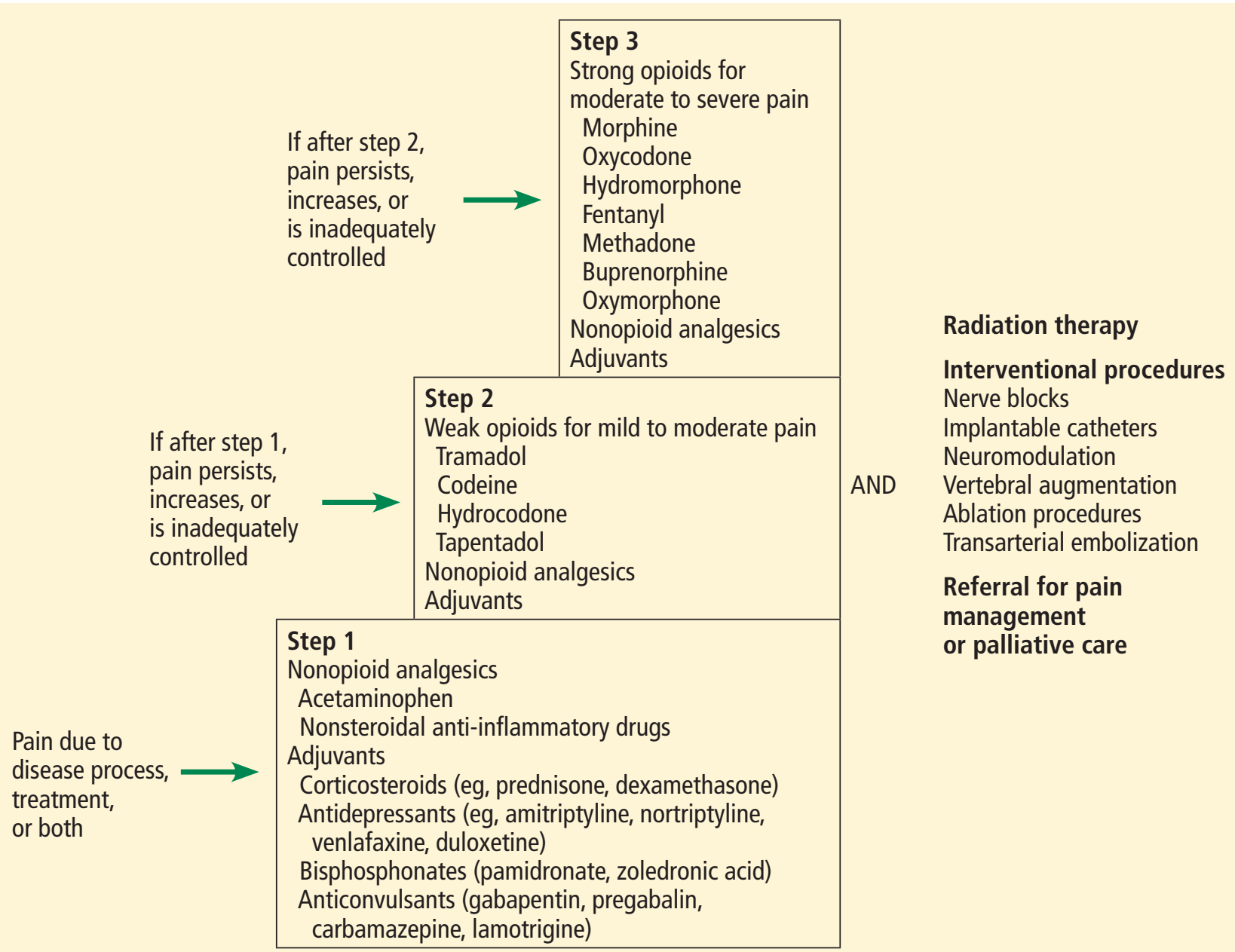

Figure 1. Our approach to managing cancer pain, based on the World Health Organization analgesic ladder.

other, nonpharmacologic interventions available for patients with cancer. It also examines pain management in cancer survivors.

\section{WHAT ARE THE KEY PRINCIPLES IN MANAGING CANCER PAIN?}

Cancer pain management often involves both drugs and procedures (Figure 1). The most commonly used framework that clinicians can employ in deciding which analgesic drugs to use is the World Health Organization (WHO) analgesic ladder. ${ }^{2,3}$

At the base, or step 1, of the 3-step ladder are nonopioid analgesics (eg, acetaminophen, nonsteroidal anti-inflammatory drugs) and adjuvants, which are used for mild pain. Adjuvants are drugs that are primarily indicated for conditions other than pain but that possess analge- sic properties; they include corticosteroids (eg, prednisone, dexamethasone), antidepressants (eg, amitriptyline, nortriptyline, venlafaxine), bisphosphonates (eg, pamidronate, zoledronic acid), and anticonvulsants (eg, gabapentin, pregabalin, carbamazepine, lamotrigine).

If pain persists or increases, weak opioids for mild to moderate pain (eg, tramadol, codeine, hydrocodone) are added in step 2. If pain remains uncontrolled, strong opioids for moderate to severe pain (eg, morphine, oxycodone, hydromorphone, fentanyl, methadone, buprenorphine) are used in step 3 .

At any stage, when cancer pain persists, escalates, or remains inadequately controlled, clinicians should consider specific nonpharmacologic interventions, which will be discussed below. Providers of ancillary services-nursing, social work, physical and occupational therapy, 
spiritual care-may need to be called in. Similarly, specialists from fields such as radiation oncology, palliative medicine, pain management, anesthesiology, interventional radiology, surgery, and orthopedics may be essential in optimizing pain control. We recommend collaborating with specialists in either palliative medicine or pain management when step 1 of the WHO analgesic ladder fails to provide ample relief, especially for providers who are uncomfortable prescribing opioids.

\section{WHAT ARE SOME OF THE NONOPIOID MEDICATIONS USED FOR CANCER PAIN?}

\section{Duloxetine, an antidepressant}

Duloxetine, a serotonin-norepinephrine reuptake inhibitor, is primarily used to treat depression and anxiety, but it is increasingly finding a place in the treatment of diabetic neuropathy, fibromyalgia, chronic back pain, and osteoarthritic pain. ${ }^{4-6}$ Recent studies suggest that duloxetine, alone or in combination with opioids and gabapentinoids (eg, gabapentin, pregabalin), also offers benefit in 2 cancer-related pain conditions, chemotherapy-induced peripheral neuropathy and cancer-related neuropathic pain., 7,8

The dosing used in studies ranged from 20 to $60 \mathrm{mg}$ per day. Common adverse effects are nausea, fatigue, and both insomnia and somnolence.

\section{Cannabinoids are not recommended}

The 2 most prominent and abundant cannabinoids-compounds derived from the Cannabis sativa plant-are tetrahydrocannabinol (THC) and cannabidiol (CBD). Preparations of cannabinoids that patients can access generally come in 3 forms:

- THC-dominant, eg, oral dronabinol and nabilone

- Balanced THC-CBD, such as oromucosal nabiximols

- CBD-dominant, such as oral CBD oil solution. ${ }^{9}$

Medical cannabis or marijuana preparations of all of these 3 forms are available and can be taken by various routes, such as by mouth, inhaled, or topical application.

Cannabinoids have been studied for the treatment of several cancer symptoms, notably pain, anorexia, nausea, and dysgeusia. Five randomized controlled trials from 2012 to 2018 were part of a systematic review of can- nabis-based medicines for cancer pain published in $2019 .{ }^{10}$ The review concluded that neither balanced THC-CBD nor THC-dominant preparations differ from placebo in reducing pain. Adverse effects of cannabinoids noted in studies include dizziness, dry mouth, nausea and vomiting, somnolence, confusion, and memory impairment. ${ }^{9,10}$ Of note, nabiximols, the cannabinoid most studied for treating cancer pain, is not currently available in the United States.

The lack of quality evidence, access issues, and worrisome side effects preclude the use of cannabinoids for cancer pain at this time.

\section{Acetaminophen}

Acetaminophen (also called paracetamol) is a nonopioid medication used in step 1 of the WHO approach to managing cancer pain. Widely available in various formulations and brands, it is a popular analgesic, formulated by itself or combined with other drugs.

With regard to cancer pain, a Cochrane systematic review in 2017 concluded that adding acetaminophen to a daily regimen of 60 $\mathrm{mg}$ or more of oral morphine results in no additional benefit in terms of pain relief, quality of life, or patient satisfaction or preference. ${ }^{11}$ The review was based on 3 randomized, placebo-controlled trials with 122 participants, in which the daily acetaminophen dose ranged from 3,000 mg to 4,000 mg. ${ }^{12-14}$ The reviewers also noted that they could find no study that used acetaminophen alone for cancer pain.

Based on these findings, acetaminophen may not be of benefit when used in step 3 of the $\mathrm{WHO}$ analgesic ladder.

\section{WHAT ARE SOME OF THE NEW OPIOID MEDICATIONS FOR CANCER PAIN?}

\section{Adjuvants are drugs that are primarily indicated for conditions other than pain but possess analgesic properties}

\section{Tapentadol, a mu agonist and norepinephrine reuptake inhibitor}

Tapentadol has a unique synergistic mechanism of action, functioning as both a weak mu-opioid agonist and a norepinephrine reuptake inhibitor, making it the first in a new drug class. ${ }^{15-17}$ While tapentadol has 50 times less affinity for the mu-opioid receptor and relatively moderate norepinephrine reuptake inhibitor activity, the synergy of these mechanisms generates a degree of potency comparable to that of morphine. ${ }^{17}$ 
This unique mechanism results in potential benefits. The drug causes fewer adverse effects than other opioids, especially gastrointestinal problems such as nausea, vomiting, and constipation. The time to development of tolerance is longer than with morphine, and the likelihood of abuse may be lower. ${ }^{15,16}$ Tapentadol can also be helpful in treating neuropathic pain, with a similar mechanism as tricyclic antidepressants and serotonin-norepinephrine reuptake inhibitors.

Tapentadol is available in both immediateand extended-release forms. There is currently no generic version available in the United States, and the drug may be prohibitively expensive or require prior insurance authorization.

\section{Oxymorphone, a semisynthetic mu agonist}

Oxymorphone is a semisynthetic mu-opioid agonist that is about twice as strong as oxycodone and 3 times as strong as oral morphine in relieving pain. ${ }^{18}$ It has been shown to be clinically comparable to oxycodone, and it caused less respiratory depression in 1 study. ${ }^{18}$ It is available in both immediate- and extendedrelease formulations.

The drug is predominantly metabolized in

Lack of
evidence,
access issues,
and side effects
preclude
the use of
cannabinoids
for cancer pain
at this time
the liver, and, therefore, its use is relatively contraindicated in patients who have moderate to severe liver failure..$^{15}$ Its elimination in renal failure is prolonged; hence, a longer dosing interval is recommended.

Oxymorphone has been shown to be effective and well tolerated for managing cancer pain, ${ }^{19,20}$ and can be considered for patients for whom other strong opioids such as morphine, oxycodone, and fentanyl have failed or who could not tolerate these drugs. Of note, oxymorphone, either in immediate- or extendedrelease form, generally costs more in the United States than morphine or oxycodone.

\section{New fentanyl formulations}

While intravenous and transdermal fentanyl preparations are used fairly often, a number of newer formulations are available. Transmucosal fentanyl products have been available in the form of buccal tablets, films, and intranasal sprays for a number of years, but are restricted in their use to opioid-tolerant patients (ie, those taking daily doses of at least $60 \mathrm{mg}$ oral morphine or its equivalent for at least 1 week), ${ }^{21}$ and are relatively expensive, limiting their use.
The advantages of these forms of fentanyl are rapid onset (within 10-15 minutes) and short duration of action, making them particularly beneficial in treating episodes of unpredictable breakthrough pain. ${ }^{21,22}$ Available dosages, however, do not correspond with those of other opioids, and even doses of different fentanyl formulations given by the same route are not equivalent. Each preparation must be started at the lowest available dose and titrated up to effect when starting or changing formulations.

\section{WHAT IS THE ROLE OF RADIATION THERAPY IN MANAGING CANCER PAIN?}

Radiation therapy, or radiotherapy, has various roles in treating cancer; it is given with intent to cure the disease, arrest tumor growth, or control symptoms. As a nonpharmacologic analgesic, it is effective and time-efficient. ${ }^{23}$ In particular, it should be strongly considered for patients suffering from painful bone metastases.

Radiation therapy generally is of 2 types, external beam and stereotactic. External beam radiation therapy, the conventional type, uses a fixed source of radiation directed toward cancerous tissue in the body. Stereotactic therapy, on the other hand, uses a moving source that targets the tumor from different angles, thereby limiting damage to nearby normal tissue. This type is typically selected for small or medium-sized tumors.

In either type, treatment can be delivered in single or multiple doses or fractions. A single fraction has been shown to be as efficacious as multiple fractions for alleviating pain from bone metastases. ${ }^{24}$ Of note, more patients who undergo single-fraction therapy subsequently need repeat radiation therapy to the same site compared with those who receive multiple fractions up front. ${ }^{25}$ Single-fraction therapy has the advantage of being cost-effective and convenient, especially for patients with limited life expectancy.

Of note, a transient "pain flare" can occur with radiotherapy. In a study of patients who underwent single- or multiple-fraction radiation therapy for symptomatic bone metastases, the overall incidence of pain flare within 10 days of completion was $40 \% .{ }^{26}$ The corticosteroid dexamethasone, given immediately 


\title{
TABLE 1
}

\section{Interventional procedures for cancer pain management}

Type of intervention or procedure

Primary tumor or metastatic site indications

\author{
Nerve blocks \\ Peripheral nerves \\ Paravertebral \\ Chest-wall pain after mastectomy \\ Interscalene \\ Upper-extremity pain after surgical repair of pathologic \\ fractures and neuropathy from brachial plexoplathy
}

Plexus nerves

Celiac

Right-upper-quadrant and epigastric pain from pancreaticobiliary malignancies

Superior hypogastric

Pelvic pain from gynecologic and urologic malignancies

Ganglion impar Perineal and rectal pain from anorectal and vulvar malignancies

Implantable catheters and neuromodulation

Intraspinal drug delivery

Visceral pain from abdominal malignancies, neuro-

Spinal cord stimulation

Dorsal root ganglion stimulation

pathic pain for lower extremities, and intractable back

pain from metastases

\section{Vertebral augmentation \\ Vertebroplasty \\ Kyphoplasty \\ Ablation procedures \\ Radiofrequency ablation \\ Cryoablation \\ Microwave ablation \\ Magnetic resonance imaging-guided \\ focused-ultrasound surgery \\ Transarterial embolization \\ before single-fraction therapy and daily for 4 days after, has proven to mitigate pain flares. ${ }^{27}$ \\ WHAT INTERVENTIONAL PROCEDURES ARE AVAILABLE FOR CANCER PAIN?}

Some patients with cancer experience refractory pain, defined as failure of conventional oral pharmacologic agents and tumor-directed radiation therapy to control pain or such treatment causing intolerable side effects. In this situation, interventional treatments should be considered (Table 1). However, evidence of efficacy is lacking. Most data on outcomes are based on case reports and case series, given challenges in
Back pain from spine metastases and vertebral fractures

Pain from metastatic bone and soft-tissues sites

\section{Pain from hypervascular bone metastases}

methodology such as accrual of adequate sample sizes for test populations and control groups. ${ }^{28}$

\section{Nerve blocks}

Cancer pain can affect nearly any anatomic site and may need local control using nerve or neurolytic blocks, which can be achieved by chemicals (phenol or ethanol), radiofrequency (thermal) ablation, or surgery. Nerve blocks can be performed in a peripheral nerve, plexus nerve, or central neuraxial site. In theory, any peripheral nerve can be blocked, but technical difficulties (eg, scar tissue, swelling) may preclude the procedure, and outcomes cannot
In survivors, opioids need to be used carefully, with the eventual goal of weaning 
be predicted due to a dearth of evidence. ${ }^{29} \mathrm{Ex}$ amples of localized nerve blocks include paravertebral blocks for patients undergoing breast surgery $^{30}$ and interscalene blocks for surgical repair of pathologic fractures. ${ }^{31}$

Celiac plexus blocks are often used and are well studied in treating abdominal pain from pancreaticobiliary cancers. They have been shown to lower pain scores and decrease opioid use. ${ }^{32-35}$ Ultrasonography-guided endoscopic celiac plexus blocks have also been performed. Though mostly based on case reports and low-quality studies with small sample sizes, positive outcomes have been described. ${ }^{36,37}$

Blocks to the superior hypogastric plexus for pelvic pain from gynecologic and urologic malignancies and to the ganglion impar (ganglion of Walther) for perineal pain secondary to anorectal tumors have been shown to resolve pain. ${ }^{38,39}$ Injection can be done into the intrathecal space to achieve segmental pain control without affecting motor function. ${ }^{40}$

Implantable catheters and neuromodulation For intractable tumor-related abdominal pain, neuropathic pain in extremities, or somatic low-back pain, another method of achieving
Managing cancer pain across its disease trajectory is complex central neuraxial analgesia is to use a percutaneous or implanted catheter to deliver opioids, local anesthetics, and adjuvant analgesics into the epidural or intrathecal space. ${ }^{28}$ The dose is smaller than a systemic dose, and this route would likely benefit an individual having severe adverse effects from systemic opioid therapy. ${ }^{41,42}$

A randomized controlled trial in $202 \mathrm{pa}-$ tients with advanced cancer compared medical management alone vs intrathecal delivery plus medical management. The latter was associated with lower pain scores, fewer side effects, and increased survival. ${ }^{43,44}$

Neuromodulation is the delivery of electricity to peripheral nerves, spinal cord, and brain. Spinal cord stimulation is commonly used to treat neuropathic pain from failed back syndromes, ischemic limbs, and complex regional pain syndromes, even though there is a paucity of evidence. ${ }^{45}$ It has been applied to cancer pain and shown to decrease pain scores and opioid use, based on case reports. ${ }^{46-48}$ Reports of dorsal root ganglion stimulation may help pain from surgery, complex regional pain syndrome and phantom pain, and may be considered for refractory neuropathic cancer pain. ${ }^{49}$

\section{Vertebral augmentation}

Vertebral augmentation involves injecting polymethyl methacrylate, a cement, directly into the vertebral body (vertebroplasty) or through a balloon (kyphoplasty). Patients with vertebral compression fractures from spinal metastases may benefit from either procedure.

Kyphoplasty was shown to improve pain scores, decrease opioid use, and improve quality of life compared with medical management alone in a randomized controlled trial in 134 patients with cancer. ${ }^{50}$ Several studies showed improved pain scores and physical function after this procedure in patients with painful, cancer-related vertebral fractures. ${ }^{51-53}$

\section{Ablation procedures}

Imaging-guided tumor ablation involves destruction of bone or soft tissue using radiofrequency energy, cold (cryoablation), microwave energy, or magnetic resonance imaging-guided focused ultrasound.

Radiofrequency ablation has been the most used. Patients experienced reduced pain scores and improved mood after the procedure. ${ }^{54-56}$ Combined radiofrequency ablation and cementoplasty, in which cement is injected into bone for stabilization, have been shown to improve outcomes, as the latter provides structural stability to bone destroyed by the ablation. ${ }^{57-59}$

Patients treated with cryoablation experienced improved pain scores, decreased opioid use, and durable effects (ie, lasting 24 weeks or more). ${ }^{60-63}$

A prospective 1-year study of computed tomography-guided microwave ablation of bone metastases and soft-tissue sarcomas demonstrated a success rate (defined as $\geq 80 \%$ tumor necrosis) of $80 \%$ at 1 month and $63 \%$ at 12 months. ${ }^{64}$ Combined with cementoplasty, microwave ablation decreased pain scores and improved ambulation in a retrospective study of 35 cancer patients with high risk of fracture. ${ }^{65}$

Magnetic resonance imaging-guided focused ultrasound provides more defined tumor margins for a more accurate target ablation. ${ }^{66}$ Case series from both single centers and multiple centers showed improved pain scores and decreased opioid analgesic use. ${ }^{67,68}$ 


\section{Transarterial embolization}

Often, before orthopedic surgery, an occlusive material is injected intra-arterially to prevent perioperative bleeding from potentially bloody bone metastases. ${ }^{69}$ This practice, called transarterial embolization, has provided pain relief for metastatic bone disease in several case series. ${ }^{70-72}$

\section{HOW IS PAIN MANAGED IN CANCER SURVIVORS?}

Over the years, effective treatments and innovations have yielded remarkably improved life expectancy and cure rates for patients with most types of cancer. Unfortunately, more than a third of survivors continue to suffer from cancer pain. ${ }^{1}$

Chronic pain in these patients can be caused by any of the 3 primary anticancer treatment approaches-chemotherapy, radiation therapy, or surgery (Table 2). ${ }^{73,74}$ Many patients undergo a combination of these treatments, resulting in complex pain. Other causes of chronic pain include lymphedema, osteoporosis leading to pathologic fractures, and adjuvant drugs (eg, aromatase inhibitors, used to treat breast cancer, which cause myalgia and arthralgia).

Pain management in cancer survivors mirrors the interdisciplinary and multimodal approach for treating pain in patients undergoing active treatment. Rather than an ongoing search for a cure of the pain, preserving function and adopting coping strategies become the focus for survivors. ${ }^{73}$

In managing these patients, it is crucial to thoroughly assess new or worsening pain, especially when accompanied by such symptoms as unexplained weight loss, unusual fatigue, altered bladder or bowel function, persistent cough, focal numbness or weakness, or an enlarging mass. ${ }^{74}$ This allows prompt diagnosis of cancer recurrence or progression.

The WHO pain relief ladder remains the framework for starting analgesics, with close attention to employing adjuvant medications to control neuropathic pain. Opioids need to be used carefully, and with the eventual goal of weaning. Nonpharmacologic interventions, such as nerve blocks, may be indicated for patients with refractory surgery-related pain. Patients who acquire the tendency to cata-

\section{TABLE 2}

\section{Causes of chronic pain associated with cancer treatment}

Chemotherapy

Peripheral neuropathy (with agents such as paclitaxel, docetaxel, vincristine, cisplatin, oxaliplatin, thalidomide, and bortezomib)

Osteonecrosis secondary to concurrent steroid use

\section{Radiation therapy}

Connective-tissue fibrosis

Neural damage (such as brachial plexopathy, myelopathy)

Pain from secondary malignancies

Enteritis

Proctitis

Cystitis

Vaginal dryness or atrophy

\section{Surgery}

Mastectomy (may be due to phantom breast pain, intercostobrachial neuralgia, neuroma or nerve injury)

Amputation or phantom limb pain

Thoracotomy

Head and neck surgery (eg, neck dissection)

strophize or exaggerate their pain may benefit from psychosocial support provided by a social worker, psychologist, or spiritual counselor. Referral for physical therapy, occupational therapy, or both may be necessary to improve functional status in the face of chronic pain.

\section{A COMPREHENSIVE APPROACH TO A COMPLEX PROBLEM}

Managing cancer pain across its disease trajectory is complex. A comprehensive, interdisciplinary, and multimodal approach combining pharmacologic and nonpharmacologic interventions provided by various disciplines and medical specialties is vital.

Acknowledgments: We would like to thank Beth Faiman, $\mathrm{PhD}, \mathrm{MSN}$, for reviewing our article and sharing her valuable comments.

\section{DISCLOSURES}

The authors report no relevant financial relationships which, in the context of their contributions, could be perceived as a potential conflict of interest. 


\section{CANCER PAIN}

\section{REFERENCES}

1. van den Beuken-van Everdingen $M H$, Hochstenbach $L M$, Joosten EA, Tjan-Heijnen VC, Janssen DJ. Update on prevalence of pain in patients with cancer: systematic review and meta-analysis. J Pain Symptom Manage 2016; 51(6):1070-1090.e9. doi:10.1016/j.jpainsymman.2015.12.340

2. Induru RR, Lagman RL. Managing cancer pain: frequently asked questions. Cleve Clin J Med 2011; 78(7):449-464. doi:10.3949/ccjm.78a.10054

3. World Health Organization. Palliative care. Cancer pain ladder for adults. Accessed February 9, 2021. https://www.who.int/cancer/palliative/painladder/en/

4. Hossain SM, Hussain SM, Ekram AR. Duloxetine in painful diabetic neuropathy: a systematic review. Clin J Pain 2016; 32(11):1005-1010. doi:10.1097/AJP.0000000000000343

5. Lunn MP, Hughes RA, Wiffen PJ. Duloxetine for treating painful neuropathy, chronic pain or fibromyalgia. Cochrane Database Syst Rev 2014; (1):CD007115. doi:10.1002/14651858.CD007115.pub3

6. Wang ZY, Shi SY, Li SJ, et al. Efficacy and safety of duloxetine on osteoarthritis knee pain: a meta-analysis of randomized controlled trials. Pain Med 2015; 16(7):1373-1385. doi:10.1111/pme.12800

7. Smith EM, Pang H, Cirrincione $\mathbf{C}$, et al. Effect of duloxetine on pain, function, and quality of life among patients with chemotherapyinduced painful peripheral neuropathy: a randomized clinical trial. JAMA 2013; 309(13):1359-1367. doi:10.1001/jama.2013.2813

8. Matsuoka H, Iwase S, Miyaji T, et al. Additive duloxetine for cancerrelated neuropathic pain nonresponsive or intolerant to opioidpregabalin therapy: a randomized controlled trial (JORTC-PAL08). J Pain Symptom Manage 2019; 58(4):645-653. doi:10.1016/j.jpainsymman.2019.06.020

9. Steele G, Arneson T, Zylla D. A comprehensive review of cannabis in patients with cancer: availability in the USA, general efficacy, and safety. Curr Oncol Rep 2019; 21(1):10. doi:10.1007/s11912-019-0757-7

10. Häuser W, Welsch P, Klose P, Radbruch L, Fitzcharles MA. Efficacy, tolerability and safety of cannabis-based medicines for cancer pain: a systematic review with meta-analysis of randomised controlled trials. Schmerz 2019; 33(5):424-436. doi:10.1007/s00482-019-0373-3

11. Wiffen PJ, Derry S, Moore RA, et al. Oral paracetamol (acetaminophen) for cancer pain. Cochrane Database Syst Rev 2017; 7(7):CD012637. doi:10.1002/14651858.CD012637.pub2

12. Axelsson $B$, Borup $S$. Is there an additive analgesic effect of paracetamol at step 3? A double-blind randomized controlled study. Palliat Med 2003; 17(8):724-725. doi:10.1177/026921630301700816

13. Cubero DI, del Giglio A. Early switching from morphine to methadone is not improved by acetaminophen in the analgesia of oncologic patients: a prospective, randomized, double-blind, placebo-controlled study. Support Care Cancer 2010; 18(2):235-242. doi:10.1007/s00520-009-0649-8

14. Israel FJ, Parker G, Charles M, Reymond L. Lack of benefit from paracetamol (acetaminophen) for palliative cancer patients requiring high-dose strong opioids: a randomized, double-blind, placebo-controlled, crossover trial. J Pain Symptom Manage 2010; 39(3):548-554. doi:10.1016/j.jpainsymman.2009.07.008

15. Vadivelu N, Chang D, Helander EM, et al. Ketorolac, oxymorphone, tapentadol, and tramadol: a comprehensive review. Anesthesiol Clin 2017; 35(2):e1-e20. doi:10.1016/j.anclin.2017.01.001

16. Kress HG, Coluzzi F. Tapentadol in the management of cancer pain: current evidence and future perspectives. J Pain Res 2019; 12:1553-1560. doi:10.2147/JPR.S191543

17. Romualdi P, Grilli M, Canonico PL, Collino M, Dickenson AH. Pharmacological rationale for tapentadol therapy: a review of new evidence. J Pain Res 2019; 12:1513-1520. doi:10.2147/JPR.S190160

18. Babalonis S, Lofwall MR, Nuzzo PA, Walsh SL. Pharmacodynamic effects of oral oxymorphone: abuse liability, analgesic profile and direct physiologic effects in humans. Addict Biol 2016; 21(1):146158. doi:10.1111/adb.12173

19. Mayyas F, Fayers P, Kaasa S, Dale O. A systematic review of oxymor- phone in the management of chronic pain. J Pain Symptom Manage 2010; 39(2):296-308. doi:10.1016/j.jpainsymman.2009.07.010

20. Slatkin NE, Rhiner MI, Gould EM, Ma T, Ahdieh H. Long-term tolerability and effectiveness of oxymorphone extended release in patients with cancer. J Opioid Manag 2010; 6(3):181-191. doi:10.5055/jom.2010.0016

21. Brząkała J, Leppert $\mathbf{W}$. The role of rapid onset fentanyl products in the management of breakthrough pain in cancer patients. Pharmacol Rep 2019; 71(3):438-442. doi:10.1016/j.pharep.2019.01.010

22. Fallon $\mathbf{M}$, Giusti R, Aielli F, et al. Management of cancer pain in adult patients: ESMO Clinical Practice Guidelines. Ann Oncol 2018; 29(suppl 4): iv166-iv191. doi:10.1093/annonc/mdy152

23. Hartsell WF, Scott CB, Bruner DW, et al. Randomized trial of shortversus long-course radiotherapy for palliation of painful bone metastases. J Natl Cancer Inst 2005; 97(11):798-804. doi:10.1093/jnci/dji139

24. Chow R, Hoskin P, Schild SE, et al. Corrigendum to "Single vs multiple fraction palliative radiation therapy for bone metastases: cumulative meta-analysis." Radiother Oncol 2020; 148:115. doi:10.1016/j.radonc.2020.01.031

25. Howell DD, James JL, Hartsell WF, et al. Single-fraction radiotherapy versus multifraction radiotherapy for palliation of painful vertebral bone metastases-equivalent efficacy, less toxicity, more convenient: a subset analysis of Radiation Therapy Oncology Group trial 97-14. Cancer 2013; 119(4):888-896. doi:10.1002/cncr.27616

26. Hird A, Chow E, Zhang L, et al. Determining the incidence of pain flare following palliative radiotherapy for symptomatic bone metastases: results from three Canadian cancer centers. Int J Radiat Oncol Biol Phys 2009; 75(1):193-197. doi:10.1016/j.ijrobp.2008.10.044

27. Chow E, Meyer RM, Ding K, et al. Dexamethasone in the prophylaxis of radiation-induced pain flare after palliative radiotherapy for bone metastases: a double-blind, randomised placebo-controlled, phase 3 trial. Lancet Oncol 2015; 16(15):1463-1472. doi:10.1016/S1470-2045(15)00199-0

28. Vayne-Bossert P, Afsharimani B, Good P, Gray P, Hardy J. Interventional options for the management of refractory cancer pain-what is the evidence?. Support Care Cancer 2016; 24(3):1429-1438. doi:10.1007/s00520-015-3047-4

29. Chambers WA. Nerve blocks in palliative care. Br J Anaesth 2008; 101(1):95-100. doi:10.1093/bja/aen105

30. Andreae $\mathbf{M H}$, Andreae DA. Local anaesthetics and regional anaesthesia for preventing chronic pain after surgery. Cochrane Database Syst Rev 2012;10:CD007105. doi:10.1002/14651858.CD007105.pub2

31. Falyar CR, Grossman EC. Ultrasound-guided interscalene-supraclavicular block for an intramedullary nailing of a pathologic humeral fracture: practical application of ultrasound-guided regional anesthesia. AANA J 2014; 82(3):219-222. pmid:25109160

32. Zhong W, Yu Z, Zeng JX, et al. Celiac plexus block for treatment of pain associated with pancreatic cancer: a meta-analysis. Pain Pract 2014; 14(1):43-51. doi:10.1111/papr.12083

33. Wong GY, Schroeder DR, Carns PE, et al. Effect of neurolytic celiac plexus block on pain relief, quality of life, and survival in patients with unresectable pancreatic cancer: a randomized controlled trial. JAMA 2004; 291(9):1092-1099. doi:10.1001/jama.291.9.1092

34. Staats PS, Hekmat $H$, Sauter P, Lillemoe $K$. The effects of alcohol celiac plexus block, pain, and mood on longevity in patients with unresectable pancreatic cancer: a double-blind, randomized, placebo-controlled study. Pain Med 2001; 2(1):28-34. doi:10.1046/j.1526-4637.2001.002001028.x

35. Eisenberg E, Carr DB, Chalmers TC. Neurolytic celiac plexus block for treatment of cancer pain: a meta-analysis. Anesth Analg 1995; 80(2):290-295. doi:10.1097/00000539-199502000-00015

36. Arcidiacono PG, Calori G, Carrara S, McNicol ED, Testoni PA. Celiac plexus block for pancreatic cancer pain in adults. Cochrane Database Syst Rev 2011; 2011(3):CD007519. doi:10.1002/14651858.CD007519.pub2

37. Puli SR, Reddy JB, Bechtold ML, Antillon MR, Brugge WR. EUS-guided celiac plexus neurolysis for pain due to chronic pancreatitis or pancreatic cancer pain: a meta-analysis and systematic review. Dig 
Dis Sci 2009; 54(11):2330-2337. doi:10.1007/s10620-008-0651-x

38. Hou S, Novy D, Felice F, Koyyalagunta D. Efficacy of superior hypogastric plexus neurolysis for the treatment of cancer-related pelvic pain. Pain Med 2020; 21(6):1255-1262. doi:10.1093/pm/pnz151

39. Sousa Correia J, Silva M, Castro C, Miranda L, Agrelo A. The efficacy of the ganglion impar block in perineal and pelvic cancer pain. Support Care Cancer 2019; 27(11):4327-4330. doi:10.1007/s00520-019-04738-9

40. Watanabe A, Yamakage $M$. Intrathecal neurolytic block in a patient with refractory cancer pain. J Anesth 2011; 25(4):603-605. doi:10.1007/s00540-011-1141-4

41. Sindt JE, Brogan SE. Interventional treatments of cancer pain. Anesthesiol Clin 2016; 34(2):317-339. doi:10.1016/j.anclin.2016.01.004

42. Smith TJ, Swainey C, Coyne PJ. Pain management, including intrathecal pumps. Curr Pain Headache Rep 2005; 9(4):243-248. doi:10.1007/s11916-005-0031-6

43. Smith TJ, Staats PS, Deer T, et al. Randomized clinical trial of an implantable drug delivery system compared with comprehensive medical management for refractory cancer pain: impact on pain, drug-related toxicity, and survival. J Clin Oncol 2002; 20(19):4040 4049. doi:10.1200/JCO.2002.02.118

44. Smith TJ, Coyne PJ. Implantable drug delivery systems (IDDS) after failure of comprehensive medical management (CMM) can palliate symptoms in the most refractory cancer pain patients. J Palliat Med 2005; 8(4):736-742. doi:10.1089/jpm.2005.8.736

45. Kunnumpurath S, Srinivasagopalan R, Vadivelu N. Spinal cord stimulation: principles of past, present and future practice: a review. J Clin Monit Comput 2009; 23(5):333-339. doi:10.1007/s10877-009-9201-0

46. Lihua P, Su M, Zejun Z, Ke W, Bennett MI. Spinal cord stimulation for cancer-related pain in adults. Cochrane Database Syst Rev 2013; (2):CD009389. doi:10.1002/14651858.CD009389.pub2

47. Yakovlev AE, Resch BE. Spinal cord stimulation for cancerrelated low back pain. Am J Hosp Palliat Care 2012; 29(2):93-97. doi:10.1177/1049909111410414

48. Yakovlev AE, Ellias Y. Spinal cord stimulation as a treatment option for intractable neuropathic cancer pain. Clin Med Res 2008; 6(3-4):103-106. doi:10.3121/cmr.2008.813

49. Harrison C, Epton S, Bojanic S, Green AL, FitzGerald JJ. The efficacy and safety of dorsal root ganglion stimulation as a treatment for neuropathic pain: a literature review. Neuromodulation 2018; 21(3):225-233. doi:10.1111/ner.12685

50. Berenson J, Pflugmacher R, Jarzem P, et al. Balloon kyphoplasty versus non-surgical fracture management for treatment of painful vertebral body compression fractures in patients with cancer: a multicentre, randomised controlled trial. Lancet Oncol 2011; 12(3):225235. doi:10.1016/S1470-2045(11)70008-0

51. Burton AW, Mendoza T, Gebhardt R, et al. Vertebral compression fracture treatment with vertebroplasty and kyphoplasty: experience in 407 patients with 1,156 fractures in a tertiary cancer center. Pain Med 2011; 12(12):1750-1757. doi:10.1111/j.1526-4637.2011.01278.x

52. Chew C, Craig L, Edwards R, Moss J, O’Dwyer PJ. Safety and efficacy of percutaneous vertebroplasty in malignancy: a systematic review. Clin Radiol 2011; 66(1):63-72. doi:10.1016/j.crad.2010.09.011

53. Schroeder JE, Ecker E, Skelly AC, Kaplan L. Cement augmentation in spinal tumors: a systematic review comparing vertebroplasty and kyphoplasty. Evid Based Spine Care J 2011; 2(4):35-43. doi:10.1055/s-0031-1274755

54. Dupuy DE, Liu D, Hartfeil D, et al. Percutaneous radiofrequency ablation of painful osseous metastases: a multicenter American College of Radiology Imaging Network trial. Cancer 2010; 116(4):989997. doi:10.1002/cncr.24837

55. Callstrom MR, Charboneau JW, Goetz MP, et al. Image-guided ablation of painful metastatic bone tumors: a new and effective approach to a difficult problem. Skeletal Radiol 2006; 35(1):1-15. doi:10.1007/s00256-005-0003-2

56. Goetz MP, Callstrom MR, Charboneau JW, et al. Percutaneous image-guided radiofrequency ablation of painful metastases involving bone: a multicenter study. J Clin Oncol 2004; 22(2):300-306.
doi:10.1200/JCO.2004.03.097

57. Hoffmann RT, Jakobs TF, Trumm C, Weber C, Helmberger TK, Reiser MF. Radiofrequency ablation in combination with osteoplasty in the treatment of painful metastatic bone disease. J Vasc Interv Radiol 2008; 19(3):419-425. doi:10.1016/j.jvir.2007.09.016

58. Munk PL, Rashid F, Heran MK, et al. Combined cementoplasty and radiofrequency ablation in the treatment of painful neoplastic lesions of bone. J Vasc Interv Radiol 2009; 20(7):903-911. doi:10.1016/j.jvir.2009.03.035

59. Clarençon F, Jean B, Pham HP, et al. Value of percutaneous radiofrequency ablation with or without percutaneous vertebroplasty for pain relief and functional recovery in painful bone metastases. Skeletal Radiol 2013; 42(1):25-36. doi:10.1007/s00256-011-1294-0

60. Callstrom MR, Atwell TD, Charboneau JW, et al. Painful metastases involving bone: percutaneous image-guided cryoablation-prospective trial interim analysis. Radiology 2006; 241(2):572-580. doi:10.1148/radiol.2412051247

61. Callstrom MR, Dupuy DE, Solomon SB, et al. Percutaneous imageguided cryoablation of painful metastases involving bone: multicenter trial. Cancer 2013; 119(5):1033-1041. doi:10.1002/cncr.27793

62. Prologo JD, Passalacqua M, Patel I, Bohnert N, Corn DJ. Imageguided cryoablation for the treatment of painful musculoskeletal metastatic disease: a single-center experience. Skeletal Radiol 2014; 43(11):1551-1559. doi:10.1007/s00256-014-1939-x

63. Tomasian A, Wallace A, Northrup B, Hillen TJ, Jennings JW. Spine cryoablation: pain palliation and local tumor control for vertebral metastases. AJNR Am J Neuroradiol 2016; 37(1):189-195. doi:10.3174/ajnr.A4521

64. Aubry S, Dubut J, Nueffer JP, Chaigneau L, Vidal C, Kastler B. Prospective 1-year follow-up pilot study of CT-guided microwave ablation in the treatment of bone and soft-tissue malignant tumours. Eur Radiol 2017; 27(4):1477-1485. doi:10.1007/s00330-016-4528-7

65. Pusceddu C, Sotgia B, Fele RM, Ballicu N, Melis L. Combined microwave ablation and cementoplasty in patients with painful bone metastases at high risk of fracture. Cardiovasc Intervent Radiol 2016; 39(1):74-80. doi:10.1007/s00270-015-1151-y

66. Tempany CM, McDannold NJ, Hynynen K, Jolesz FA. Focused ultrasound surgery in oncology: overview and principles. Radiology 2011; 259(1):39-56. doi:10.1148/radiol.11100155

67. Liberman B, Gianfelice D, Inbar Y, et al. Pain palliation in patients with bone metastases using MR-guided focused ultrasound surgery: a multicenter study. Ann Surg Oncol 2009; 16(1):140-146. doi:10.1245/s10434-008-0011-2

68. Catane R, Beck A, Inbar Y, et al. MR-guided focused ultrasound surgery (MRgFUS) for the palliation of pain in patients with bone metastases-preliminary clinical experience. Ann Oncol 2007; 18(1):163-167. doi:10.1093/annonc/mdl335

69. Gupta $\mathbf{P}$, Gamanagatti $\mathbf{S}$. Preoperative transarterial embolisation in bone tumors. World J Radiol 2012; 4(5):186-192. doi:10.4329/wjr.v4.i5.186

70. Eustatia-Rutten CF, Romijn JA, Guijt MJ, et al. Outcome of palliative embolization of bone metastases in differentiated thyroid carcinoma. J Clin Endocrinol Metab 2003; 88(7):3184-3189. doi:10.1210/jc.2003-030231

71. Barton PP, Waneck RE, Karnel FJ, Ritschl P, Kramer J, Lechner GL. Embolization of bone metastases. J Vasc Interv Radiol 1996; 7(1):81-88. doi:10.1016/s1051-0443(96)70738-8

72. Chiras J, Adem C, Vallée JN, Spelle L, Cormier E, Rose M. Selective intra-arterial chemoembolization of pelvic and spine bone metastases. Eur Radiol 2004; 14(10):1774-1780. doi:10.1007/s00330-004-2240-5

73. Burton AW, Fanciullo GJ, Beasley RD, Fisch MJ. Chronic pain in the cancer survivor: a new frontier. Pain Med 2007; 8(2):189-198. doi:10.1111/j.1526-4637.2006.00220.x

74. Davies PS. Chronic pain management in the cancer survivor: tips for primary care providers. Nurse Pract 2013; 38(6):28-39. doi:10.1097/01.NPR.0000429893.95631.63

Address: Renato V. Samala, MD, MHPE, FACP, FAAHPM, Department of Palliative and Supportive Care, Taussig Cancer Institute, CA-53, Cleveland Clinic, 9500 Euclid Avenue. Cleveland, OH 44195; samalar@ccf.org 